\title{
Article \\ Bilateral Strength Asymmetry in Elite Youth Soccer Players: Differences between Age Categories
}

\author{
Maros Kalata (D, Mikulas Hank (D), David Bujnovsky, Jakub Michalek, Matej Varjan (D), Egon Kunzmann, \\ Frantisek Zahalka (D) and Tomas Maly*
}

Sport Research Center, Faculty of Physical Education and Sport, Charles University, Jose Martiho 31, Prague 6, 16252 Prague, Czech Republic; kalata@ftvs.cuni.cz (M.K.); hank@ftvs.cuni.cz (M.H.);

bujnovky@ftvs.cuni.cz (D.B.); michalek@ftvs.cuni.cz (J.M.); varjan.matej@ftvs.cuni.cz (M.V.);

kunzmann.egon@ftvs.cuni.cz (E.K.); zahalka@ftvs.cuni.cz (F.Z.)

* Correspondence: maly@ftvs.cuni.cz; Tel.: +420-776-531-143

check for

updates

Citation: Kalata, M.; Hank, M.; Bujnovsky, D.; Michalek, J.; Varjan, M.; Kunzmann, E.; Zahalka, F.; Maly, T. Bilateral Strength Asymmetry in Elite Youth Soccer Players: Differences between Age Categories. Symmetry 2021, 13, 1982. https:// doi.org/10.3390/sym13111982

Academic Editors: Anna Mika and Łukasz Oleksy

Received: 22 September 2021

Accepted: 16 October 2021

Published: 20 October 2021

Publisher's Note: MDPI stays neutral with regard to jurisdictional claims in published maps and institutional affiliations.

Copyright: (c) 2021 by the authors. Licensee MDPI, Basel, Switzerland. This article is an open access article distributed under the terms and conditions of the Creative Commons Attribution (CC BY) license (https:/ / creativecommons.org/licenses/by/ $4.0 /)$.

\begin{abstract}
The strength asymmetry of athletes as a negative health and performance factor is increasingly being researched in sports with a high load on the dominant limb when some specific unilateral movements, such as passing, jumping, and tackling, are required. This study aimed to determine the level of isokinetic strength bilateral asymmetry (BA) among knee extensors (KEs) and knee flexors (KFs) of elite youth soccer players. The sample $(n=87)$ consisted of three age categories of under 13 (U13), under 15 (U15), and under 17 (U17) years old. Isokinetic dynamometry was used to obtain the maximum peak torque of the KEs and KFs in the dominant and non-dominant lower limbs during concentric muscle contraction. The analysis revealed significantly lower values $(p<0.05)$ of BA in KEs in U17 than in younger categories, U13 and U15, and higher values $(p<0.05)$ of BA in KFs in the U15 category than in the U17category. The majority of the players in the U15 category $(68 \%)$ reached KFs BA higher than $10 \%$ in comparison with U13 players (50\%) and U17 players (28\% of players) $(p<0.05)$. Our results showed a significant effect of age category on BA levels in young soccer players. High incidences of increased BA in the lower limbs occurred in the younger categories (U13, U15) and subsequently decreased in the later adolescent stages.
\end{abstract}

Keywords: isokinetic asymmetry; knee extensors; knee flexors; maturation; youth soccer

\section{Introduction}

Soccer is one of the most popular sports in the world, as evidenced by the number of registered players in the senior and youth categories. The sport has evolved through increased physical performance and technical competence in the last decade [1] and has a high rate of contact sport injuries (4.6 to 5.2 per $1000 \mathrm{~h}$ ) among youth players [2]. Pre-season isokinetic muscle strength testing is recommended to verify and identify soccer players at a higher risk of subsequent knee injury or hamstring muscle strain [3,4]. A strength deficit of more than $10 \%$ between the lower limbs is a risk factor for knee injury $[4,5]$. Moreover, bilateral asymmetry (BA) and flexibility of joints or limbs can lead to improper control of body movement [6]. Liporaci et al. [4] showed that BA (> 10\%) between knee extensors (KEs) increased musculoskeletal injuries up to 16-fold and ligament/meniscus injuries up to 28 -fold. BA evaluation at a low angular velocity $\left(60^{\circ} \cdot \mathrm{s}^{-1}\right)$ was presented as a predictor of non-contact leg injury [7], while a combination of pre-season isokinetic strength tests using bilateral, ipsilateral, and mixed ratios can detect up to $79 \%$ of all hamstring injuries [3]. Most soccer players prefer using one particular lower limb to kick the ball and center, which requires asymmetric motor patterns that lead to the development of asymmetric adaptations of musculoskeletal lower limb function [8]. Kalata et al. [9] reported that young athletes with predominantly symmetrical movement patterns (triathlon and sports aerobics) achieved lower BA values than athletes in asymmetric sports (tennis and volleyball). Limb asymmetry in functional performance appears to be established in early 
childhood. To reduce this risk factor for injury and ensure no further increase, targeted interventions should be initiated in athletes prior to peak high velocity (PHV) [10]. BA is also associated with back pain and the development of symptomatic unilateral lesions [11]. It was found that the BA in elite soccer players negatively affected specific skills (e.g., kicking accuracy) [12]. According to Wallace and Norton [13], the use of the non-preferred lower limb is a distinguishing feature of elite soccer players. This advantage has been noted for direction control in juggling and dribbling, movement timing to trap an approaching ball, and power and accuracy to kick a static or moving ball [14]. Although strength BA as a negative factor for health and performance is well researched in professional soccer $[3,4,7,12,15]$, we observed a paucity of literature on BA in various stages of childhood and adolescence in elite youth players. Some authors have attempted to clarify the effect of maturation $[10,16]$ and chronological or professional training age $[8,17,18]$ on the BA level; however, the conclusions vary. Atkins et al. [16] examined BA during a deep squat test and concluded that the highest imbalance was observed at the age of 13-15 years, which is closely related to the well-regarded limit of the largest maturity-related changes in physical performance [19]. Vargas et al. [18] reported an increased BA $>10 \%$ of KEs in only the under 13 (U13) age category when compared with the older age categories (U15 and U17) in young female soccer. The study by Malina [20] stated that youth male soccer players under 14 years are most vulnerable to injury, and the most common injury type and location was soft tissue and the knee joint, respectively [21]. Fousekis et al. [8] found an effect of professional training age on the level of BA because players with longer training experience showed significantly lower BA than players with shorter professional training age. One possible reason is the reduced ability to cope with pre-existing asymmetries from incomplete maturation of their kinetic and neuromuscular patterns. Contrastingly, Maly et al. [17] did not confirm a significant effect of age on BA level, although they presented higher average values of BA in KEs and knee KFs in the older categories (U19 and U21) than in the younger categories (U16 and U17).

Given the high physical load of the dominant lower limb (DL) over the non-dominant lower limb (NDL) in asymmetrical sports such as soccer, subsequent overloading associated with risk of injury, and the number of children and adolescents involved in sports during growth, there is a need to examine the prevalence of BA across various youth age categories (ACs). A reason for the lack of literature on isokinetic asymmetry in youth soccer players is undoubtedly the financial limits and the deficiency of specialized measuring equipment. This study aimed to determine the BA level for KEs and KFs in elite youth soccer players of different ACs. We hypothesize a significantly increased level of BA in the younger category (U13 and U15) compared to the older category U17.

\section{Materials and Methods}

\subsection{Study Design}

A cross-sectional design was used in this study. The research was conducted using non-invasive methods according to the ethical standards set by the Ethics Committee of the Ethical Committee of the Faculty of Physical Education and Sport, Charles University, in Prague, Czech Republic (Nr. 238/2019). Measurements were performed in accordance with the Declaration of Helsinki.

\subsection{Participants}

The monitored group consisted of 87 elite youth soccer players of different ACs (Table 1). To be included in this study in terms of elite players, all participants had to perform at least in 5 matches of the highest national league of their age category. The inclusion criteria were that all players were healthy, non-injured, and had no performance limitations in the pre-season measurement. Participant characteristics including chronological age and anthropometric data are shown in Table 1. 
Table 1. Chronological age and anthropometric data of each category.

\begin{tabular}{cccccccc}
\hline \multicolumn{7}{c}{ Mean \pm SD } \\
\hline Age Category & Players $(\boldsymbol{n})$ & Age (years) & Body Height $(\mathbf{c m})$ & Body Weight $(\mathbf{k g})$ & FieldTraining & ResistanceTraining & Match \\
\hline U13 & 32 & $11.74 \pm 0.62$ & $149.73 \pm 7.08$ & $39.95 \pm 8.49$ & $3-4 \times(60-90 \mathrm{~min})$ & $\mathrm{N}$ & $2 \times 35 \mathrm{~min}$ \\
U15 & 25 & $14.02 \pm 0.61$ & $165.11 \pm 8.24$ & $52.36 \pm 8.71$ & $4-5 \times(60-90 \mathrm{~min})$ & $\mathrm{N}$ & $2 \times 40 \mathrm{~min}$ \\
U17 & 33 & $15.77 \pm 0.34$ & $177.16 \pm 5.11$ & $68.41 \pm 7.02$ & $5-6 \times(60-90 \mathrm{~min})$ & $1 \times 60 \mathrm{~min}$ & $2 \times 45 \mathrm{~min}$ \\
\hline
\end{tabular}

Notes: SD—standard deviation, $n$-number of players, $\mathrm{cm}$-centimeters, $\mathrm{kg}$-kilograms, min—minutes, $\mathrm{N}$-none.

\subsection{Procedures}

Body height was measured using a digital stadiometer (Seca 242, Seca, Hamburg, Germany), and body weight was measured using a digital scale (Seca 769, Seca, Hamburg, Germany). An isokinetic strength evaluation with $90^{\circ}$ knee extension/flexion of the KEs and KFs during concentric muscle contraction, at an angular velocity of $60^{\circ} \cdot \mathrm{s}^{-1}$ in the sitting position, was performed using an isokinetic dynamometer (Cybex NORM ${ }^{\circledR}$, Humac, CA, USA). Limb dominance was determined by observing which leg each participant preferred to use for kicking. We assessed BA between the DL and NDL $(\mathrm{H}: \mathrm{H}$, hamstring to hamstring; $\mathrm{Q}: \mathrm{Q}$, quadriceps to quadriceps). Musculoskeletal abnormalities of the knee muscles were defined as a BA $>10 \%$ [15]. Before measurement, all participants underwent a standardized warm-up focused mainly on the quadriceps and hamstring muscle groups (5 min indoor cycling at $120 \mathrm{w} / 100$ revolutions per minute and two sets with 10 repetitions of front squats, front lunges, and glute bridges). The dynamometer was adjusted according to the instructions and individual somatic characteristics of the participants. The range of motion was $90^{\circ}$ (maximum elongation was marked and set as anatomical zero " $0^{\circ}$ "). Each participant's torso and thigh of the tested lower limb were fixed with straps for stabilization. The test protocol consisted of five submaximal concentric trials for KFs and KEs [22]. A rest interval of $20 \mathrm{~s}$ was included between standard individual sets. Subsequently, two concentric attempts were performed with maximum effort, and verbal and visual feedback was provided. For further processing, the best result of the two trials was obtained.

\subsection{Statistical Analyses}

Descriptive statistics (mean and standard deviation) were calculated for all dependent variables. A Shapiro-Wilk test was used to evaluate the normality of the data distribution. The significance of differences in the observed dependent variables among AC was assessed by a two-way analysis of variance. We also determined the predominance of BA (DL or NDL). Multiple comparisons of the means of individual variables were performed using the Fisher's least significant difference post hoc test, and the effect size was assessed using the 'partial Eta squared' coefficient $\left(\eta \mathrm{p}^{2}\right)$. The coefficient values were classified as follows: $<0.10=$ small, $0.011-0.059=$ small to medium, $0.060-0.138=$ medium to large, and $>0.139=$ large. Pearson's $\chi 2$ test was used to compare the prevalence of BA $(>10 \%)$ among various groups, and the effect size was assessed using the phi coefficient. The phi coefficient values of $0.1,0.3$, and 0.5 are considered small, medium, and large effects, respectively. For all analyses, the statistical significance level for the rejection of the null hypothesis was set at $p<0.05$.

\section{Results}

\subsection{Isokinetic Strength of Knee Extensors and Flexors}

AC had a significant effect $(p<0.001)$ on the peak torque $(\mathrm{PT})$ for KEs and KFs (PT ${ }^{\mathrm{KE}}$ and $\mathrm{PT}^{\mathrm{KF}}$ ) for DL and NDL. Post hoc analysis revealed that the U17 category had higher $\mathrm{PT}^{\mathrm{KE}}$ and $\mathrm{PT}^{\mathrm{KF}}$ for DL and NDL than younger ACs, namely, U13 and U15. The U15 category also achieved significantly higher $(p<0.001) \mathrm{PT}^{\mathrm{KE}}$ and $\mathrm{PT}^{\mathrm{KF}}$ values than the U13 category (Table 2). 
Table 2. Bilateral ratio of knee extensors and flexors and maximal peak torque in relative values $\left(\mathrm{N} \cdot \mathrm{m} \cdot \mathrm{kg}^{-1}\right)$ in age categories $\mathrm{U} 13, \mathrm{U} 15$, and U17.

\begin{tabular}{ccccccc}
\hline & U13 Mean \pm SD & U15 Mean \pm SD & U17Mean \pm SD & F & $p$ & $\eta^{2}$ \\
\hline PT KE DL $^{\text {KE }}$ & $1.69 \pm 0.53$ & $2.47 \pm 0.35^{\mathrm{b}}$ & $2.97 \pm 0.34^{\mathrm{a}}$ & 53.364 & $<0.001$ & 0.629 \\
PT $^{\mathrm{KE}}$ NDL & $1.68 \pm 0.55$ & $2.54 \pm 0.29^{\mathrm{b}}$ & $3.00 \pm 0.36^{\mathrm{a}}$ & 54.425 & $<0.001$ & 0.650 \\
PT KF $^{\mathrm{K}}$ & $1.25 \pm 0.19$ & $1.47 \pm 0.23^{\mathrm{b}}$ & $1.75 \pm 0.20^{\mathrm{a}}$ & 47.340 & $<0.001$ & 0.530 \\
PT $^{\text {KF }} \mathrm{NDL}$ & $1.23 \pm 0.19$ & $1.38 \pm 0.18^{\mathrm{b}}$ & $1.75 \pm 0.26^{\mathrm{a}}$ & 46.977 & $<0.001$ & 0.528 \\
Q:Q (\%) & $11.10 \pm 7.59$ & $10.49 \pm 7.06$ & $6.29 \pm 5.61^{\mathrm{c}}$ & 4.456 & $<0.05$ & 0.099 \\
H:H (\%) & $11.87 \pm 7.77$ & $12.12 \pm 5.52$ & $7.79 \pm 5.81^{\mathrm{d}}$ & 3.547 & $<0.05$ & 0.081 \\
\hline
\end{tabular}

Notes: Q:Q—bilateral asymmetry ratio of knee extensors, H:H—bilateral asymmetry ratio of knee flexors, DL-dominant lower limb, $\mathrm{NDL}$-non-dominant lower limb, $\mathrm{PT}^{\mathrm{KE}}$ —-maximal peak torque of knee extensors/normalized to body mass, $\mathrm{PT}$ KF - maximal peak torque of knee flexors/normalized to body mass, SD—standard deviation, $p$ — probability of significant differences in compared means, $\eta p^{2}$ - partial eta squared coefficient of effect size, a - significantly higher $(p<0.001)$ values than those in U13 and U15 categories, b-significantly higher $(p<0.001)$ values than those in U13 category, c-significantly lower $(p<0.05)$ values than those in U15 and U13 categories, d-significantly lower $(p<0.05)$ values than those in U15 category.

\subsection{Bilateral Ratio of Knee Extensors}

The main factor, $\mathrm{AC}$, was found to have a significant effect on the BA level in KEs $\left(\mathrm{F}=4.456, p<0.05, \eta p^{2}=0.099\right)$, and the predominance of BA was detected to be insignificant $\left(\mathrm{F}=1.257, p>0.05, \eta \mathrm{p}^{2}=0.015\right)$. The interaction between the two factors was insignificant $\left(\mathrm{F}=0.159, p>0.05, \eta \mathrm{p}^{2}=0.008\right)$. Post hoc analysis revealed significant differences between the U17 and younger categories (U13 and U15) (Table 2).

\subsection{Bilateral Ratio of Knee Flexors}

Similarly, AC was found to have a significant effect on the BA level in $\mathrm{KFs}(\mathrm{F}=3.547$, $\left.p<0.05, \eta p^{2}=0.081\right)$, and the predominance of BA was insignificant $(\mathrm{F}=1.224, p>0.05$, $\left.\eta \mathrm{p}^{2}=0.015\right)$. The interaction between the two factors was also insignificant $(\mathrm{F}=0.498$, $\left.p>0.05, \eta p^{2}=0.012\right)$. The post-hoc test revealed significantly higher $(p<0.05)$ values of BA in KFs in the U15 category than in the U17 category $(12.12 \% \pm 5.52 \%$ vs. $77.79 \% \pm 5.81 \%$, respectively; Table 2).

The effect of AC on the prevalence of BA $(>10 \%)$ of KEs was determined to be insignificant $(\chi 2=5.574, p>0.05)$. The strength of the relationship between the variables was small (phi $=0.249)$. A higher proportion of players with BA $(>10 \%)$ of the KEs was observed in the U15 (52\%) category than in U13 (40\%) and U17 (22\%) categories (Figure 1).

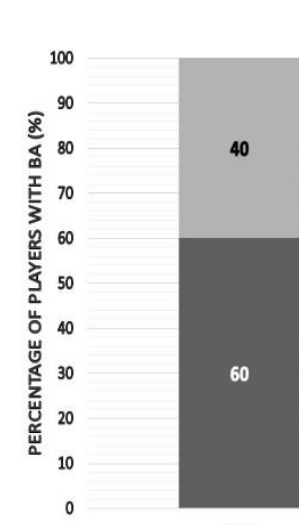

U13

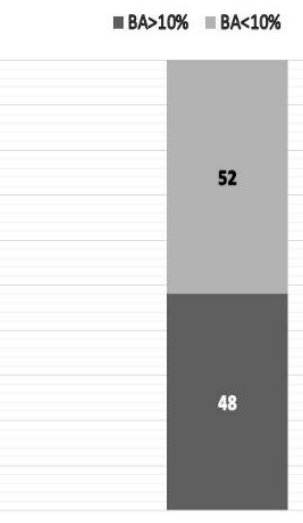

U15

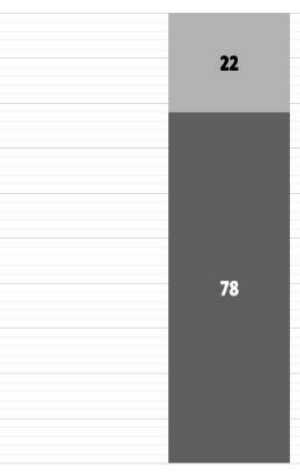

U17

Figure 1. Percentage of players with BA (>10\%) of knee extensors (Q:Q).

AC was found to have a significant effect on the prevalence of BA $(>10 \%)\left(\chi^{2}=8.998\right.$, $p<0.05)$. The strength of the relationship between the variables was medium $(\mathrm{phi}=0.316)$. The prevalence of BA was observed to be significantly higher in the U15 $(68 \%)$ category than in U13 $(50 \%)$ and U17 $(28 \%)$ categories $(p<0.05)$ (Figure 2$)$. 


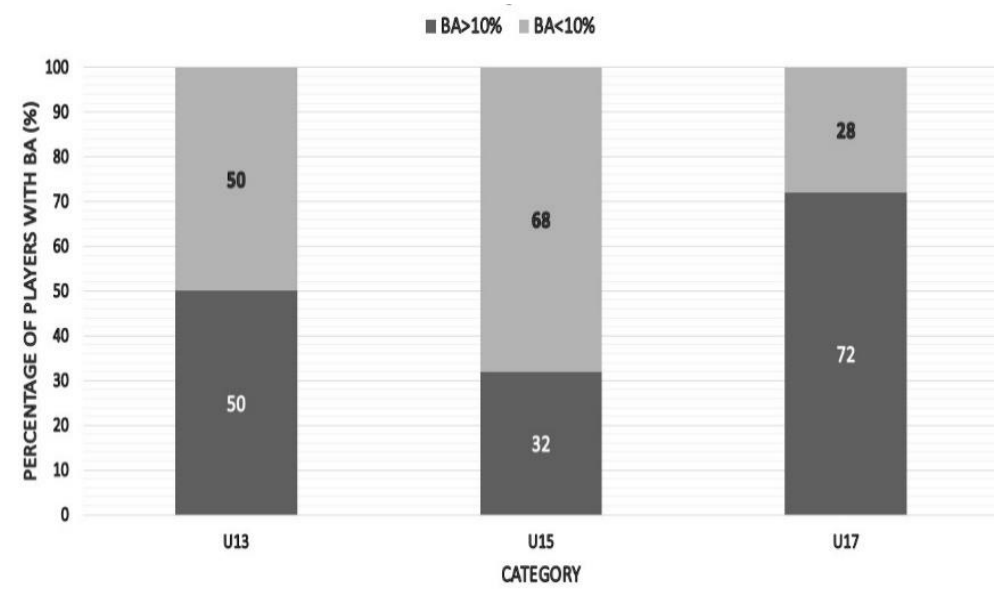

Figure 2. Percentage of players with BA (>10\%) among knee flexors (H:H).

\section{Discussion}

This study aimed to determine the isokinetic muscle strength and BA levels in the KEs and KFs of elite youth soccer players categorized by age. Our results showed a corresponding increase in muscle strength with a higher AC of youth soccer players, which is consistent with those of another study [23]. In contrast, Andrade et al. [24] reported significant differences in maximal $\mathrm{PT}^{\mathrm{KE}}$ between the categories U13 and U15, but no differences between categories U15 and U18 in female soccer players. One possibility is the difference in physiological characteristics between sexes and earlier maturation in girls.

The main finding of our study was the significant $(p<0.05)$ effect of the AC on the prevalence of BA in KEs and KFs among the analyzed categories (U13, U15, and U17). However, the study by Maly et al. [17] did not confirm this finding in their analysis of the U16-U21 categories. The study presented lower BA average values $(\mathrm{Q}: \mathrm{Q}=7.97-$ $9.29 \%, \mathrm{H}: \mathrm{H}=7.94-11.47 \%)$ than those in our study $(\mathrm{Q}: \mathrm{Q}=6.29-11.10 \%, \mathrm{H}: \mathrm{H}=7.79$ $12.12 \%$ ), suggesting that longer playing and training durations improve the neuromuscular environment; thus, athletes become more resilient and BA appears to be stabilized [25]. Notably, each category in the study (U16-U21) also underwent resistance training once a week, whereas only those in the U17 category underwent resistance training in our study. Fousekis et al. [8] demonstrated lower isokinetic strength asymmetry in adult soccer players with longer training experience ( $>10$ years) than in players with short to intermediate training experience (5-10 years). Similar results were reported by Atkins et al. [16], who aimed to determine whether elite young soccer players experience bilateral lower body imbalance during a deep functional squat test. The highest imbalance was observed at the age of 13-15 years, which is closely related to the limitations of the largest changes in physical performance [19]. Read et al. [10] also reported increased lower limb asymmetry in young (10-18 years) soccer players performing functional performance tasks (Y-balance test, single-leg horizontal hop for distance, single-leg countermovement jump, and single-leg 75\% horizontal hop); however, in most cases, maturation had no significant effect on BA levels. Asymmetry of limbs in functional performance seems to be introduced in early childhood (before PHV), which was consistent in this study, wherein the U13 category recorded significantly higher BA values in KEs than those in the U17 category (Q:Q $=11.9 \% \pm 7.59 \%$ vs. $6.8 \% \pm 5.61 \%$ ). Renshaw and Goodwin [19] stated that injuries are highest among players aged 15 years (80 injuries per $1000 \mathrm{~h}$ of exercise). Since BA prevalence is a possible contributing factor to an increased risk of injury, the introduction of targeted training programs for elimination should be considered as an effective strategy for minimizing the negative impacts of injury on young players [26]. We must add that only U17 players undergo strength resistance training once a week, which is reflected in the study findings. Further, there is a limited number of specialists who focus on the health and fitness of players in the youth categories for most teams, and it is complicated to individualize the training process. Moreover, insufficient compensation 
increases the risk of permanent tissue damage due to the load on the tissue exceeding its tolerance, particularly in unilateral activities [27]. Our results did not show significant differences in the predominance of BA in KEs and KFs according to the direction to the DL or NDL. In contrast, Rahnama et al. [15] found bilateral strength differences in KF muscles of the DL and NDL, in which those in the DL were weaker in elite and sub-elite soccer players (aged $23.4 \pm 3.8$ years). The muscle strength difference between the DL and NDL may be secondary to the difference in function during kicking. The knee of the NDL is flexed so that its flexor muscles stabilize the joints, support the weight of the body, and resist the reaction of the torque developed by the opposite limb. This biomechanical situation may act as a differential training stimulus for the KFs strength of the DL and NDL. The bilateral deficit needs to be interpreted in terms of the predominance to identify a weaker part for further targeted interventions and to reduce this bilateral deficit.

The present study reported a higher prevalence of BA ( $>10 \%)$ of KEs and KFs in the U15 category ( $52 \%$ vs. $68 \%)$ than in the U13 (40\% vs. $50 \%)$ and U17 (22\% vs. $28 \%$ of players) categories. However, our results were statistically significant $(p<0.05)$ only for KFs. Liporaci et al. [4] demonstrated a significant increase in the risk of knee injury if the asymmetry between the extensors and KFs is greater than $10 \%$ at a low angular velocity $\left(60^{\circ} \cdot \mathrm{s}^{-1}\right)$ in soccer players. This finding is concerning due to arising discussions on whether the monitoring for elite youth soccer players is adequate and sufficient in terms of physical training and injury prevention [28]. Persistent muscle performance abnormalities have been shown to cause recurrent injuries and lingering discomfort when players resume sporting activities [29]. Maly et al. [30] reported more players with BA $(>10 \%)$ in KFs (51.2\%) than BA in KEs (29.3\%) in U16 national team soccer players (15.7 \pm 0.3 years). Daneshjoo et al. [5] stated that the requirements for KE muscle groups are higher than those for KFs in specific skills such as kicking. Iga et al. [31] emphasized that the muscle loading patterns experienced by youth soccer players ( $14.9 \pm 1.1$ years) asymmetrically strengthen the knee muscles towards quadriceps dominance, which impairs the ability of the hamstrings to stabilize the muscles during knee extension. Reducing strength asymmetry between KFs is one of the most important measures for the prevention of hamstring injuries in soccer players (52 professional and 49 U20 players) [32]. It should be noted that we have no information on how many players were forced to interrupt soccer training due to injuries at an early age. Additionally, due to the time and financial constraints that are present for practitioners working with elite male youth soccer players, screening and training strategies should seek to optimize the time available by adopting individualized training programs. Targeted interventions should be based on risk factor identification using innovative approaches that are suitable for working with large groups [33].

We consider the small sample sizes in individual categories without evidence of injury frequency as the main limitation of this study. Other limits include testing in concentric mode with only a low angular velocity $\left(60^{\circ} \cdot \mathrm{s}^{-1}\right)$. In addition, biological age, which may play a role in the prevalence of asymmetry, was not considered. We recommend more frequent monitoring of abilities in terms of relative strength and endurance, as well as fatigue protocols, and sorting players by player position or performance level.

\section{Conclusions}

These results may serve as a novel benchmark for the expected level of asymmetry in a cohort of uninjured youth soccer players (U13, U15, and U17). Our findings showed a significant effect of AC on the level of BA in young soccer players. A higher incidence of BA of the lower limbs occurred in the younger categories (U13 and U15) and subsequently decreased in the later stages of adolescence. Muscle function assessments can be used to identify specific deficiencies in apparently healthy players that could predispose them to injury. Therefore, we recommend regular monitoring of strength asymmetry and targeted interventions to reduce it from the U13 category due to a higher incidence of BA. 
Physiotherapists and conditioning trainers should seek to maximize the available time by adopting individualized training strategies using unilateral exercises aimed at the weaker lower limb, which are also suitable for inclusion in group training.

Author Contributions: Conceptualization, M.K. and T.M.; methodology, M.K. and T.M.; software, M.K. and M.H.; validation, T.M., M.H. and F.Z.; formal analysis, M.K.; investigation, J.M., M.V., E.K. and D.B.; resources, M.K. and M.H.; data curation, M.K. and T.M.; writing-original draft preparation, M.K., T.M. and M.H.; writing—review and editing, M.K. and T.M.; visualization, M.K., T.M. and M.H.; supervision, T.M., M.H. and F.Z.; project administration, M.K.; funding acquisition, M.K. All authors have read and agreed to the published version of the manuscript.

Funding: The research was funded by GAUK 1488120, GACR19-12150S.

Institutional Review Board Statement: The study was conducted according to the guidelines of the Declaration of Helsinki, and approved by the Institutional Review Board of Ethical Committee of the Faculty of Physical Education and Sport, Charles University, in Prague, Czech Republic (Nr. 238/2019).

Informed Consent Statement: Informed consent was obtained from all subjects involved in the study.

Data Availability Statement: MDPI Research Data Policies.

Conflicts of Interest: The authors declare no conflict of interest.

\section{References}

1. Barnes, C.; Archer, D.; Hogg, B.; Bush, M.; Bradley, P. The evolution of physical and technical performance parameters in the English Premier League. Int. J. Sports Med. 2014, 35, 1095-1100. [CrossRef] [PubMed]

2. Le Gall, F.; Carling, C.; Reilly, T.; Vandewalle, H.; Church, J.; Rochcongar, P. Incidence of injuries in elite French youth soccer players: A 10-season study. Am. J. Sports Med. 2006, 34, 928-938. [CrossRef] [PubMed]

3. Dauty, M.; Menu, P.; Fouasson-Chailloux, A.; Ferréol, S.; Dubois, C. Prediction of hamstring injury in professional soccer players by isokinetic measurements. Muscles Ligaments Tendons J. 2016, 6, 116. [CrossRef] [PubMed]

4. Liporaci, R.F.; Saad, M.; Grossi, D.B.; Riberto, M. Clinical features and isokinetic parameters in assessing injury risk in elite football players. Int. J. Sports Med. 2019, 40, 903-908. [CrossRef]

5. Daneshjoo, A.; Rahnama, N.; Mokhtar, A.H.; Yusof, A. Bilateral and unilateral asymmetries of isokinetic strength and flexibility in male young professional soccer players. J. Hum. Kinet. 2013, 36, 45-53. [CrossRef]

6. Grygorowicz, M.; Kubacki, J.; Pilis, W.; Gieremek, K.; Rzepka, R. Selected isokinetic tests in knee injury prevention. Biol. Sport 2010, 27, 47-51. [CrossRef]

7. Kim, D.; Hong, J. Hamstring to quadriceps strength ratio and noncontact leg injuries: A prospective study during one season. Isokinet. Exerc. Sci. 2011, 19, 1-6. [CrossRef]

8. Fousekis, K.; Tsepis, E.; Vagenas, G. Lower limb strength in professional soccer players: Profile, asymmetry, and training age. J. Sports Sci. Med. 2010, 9, 364.

9. Kalata, M.; Maly, T.; Hank, M.; Michalek, J.; Bujnovsky, D.; Kunzmann, E.; Zahalka, F. Unilateral and bilateral strength asymmetry among young elite athletes of various sports. Medicina 2020, 56, 683. [CrossRef]

10. Read, P.J.; Oliver, J.L.; Myer, G.D.; Croix, M.B.D.S.; Lloyd, R.S. The effects of maturation on measures of asymmetry during neuromuscular control tests in elite male youth soccer players. Pediatr. Exerc. Sci. 2018, 30, 168-175. [CrossRef]

11. Gray, J.; Aginsky, K.D.; Derman, W.; Vaughan, C.L.; Hodges, P.W. Symmetry, not asymmetry, of abdominal muscle morphology is associated with low back pain in cricket fast bowlers. J. Sci. Med. Sport 2016, 19, 222-226. [CrossRef]

12. Maly, T.; Sugimoto, D.; Izovska, J.; Zahalka, F.; Mala, L. Effect of muscular strength, asymmetries and fatigue on kicking performance in soccer players. Int. J. Sports Med. 2018, 39, 297-303. [CrossRef] [PubMed]

13. Wallace, J.L.; Norton, K.I. Evolution of World Cup soccer final games 1966-2010: Game structure, speed and play patterns. J. Sci. Med. Sport 2014, 17, 223-228. [CrossRef] [PubMed]

14. Weigelt, M.; Memmert, D. Goal-side selection in soccer penalty kicking when viewing natural scenes. Front. Psychol. 2012, 3, 312. [CrossRef] [PubMed]

15. Rahnama, N.; Lees, A.; Bambaecichi, E. A comparison of muscle strength and flexibility between the preferred and non-preferred leg in English soccer players. Ergonomics 2005, 48, 1568-1575. [CrossRef]

16. Atkins, S.J.; Bentley, I.; Hurst, H.T.; Sinclair, J.K.; Hesketh, C. The presence of bilateral imbalance of the lower limbs in elite youth soccer players of different ages. J. Strength Cond. Res. 2016, 30, 1007-1013. [CrossRef] [PubMed]

17. Maly, T.; Ford, K.R.; Sugimoto, D.; Izovska, J.; Bujnovsky, D.; Hank, M.; Cabell, L.; Zahalka, F. Isokinetic strength, bilateral and unilateral strength differences: Variation by age and laterality in elite youth football players. Int. J. Morphol. 2021, 39. [CrossRef]

18. Vargas, V.Z.; Peres, B.; Vancini, R.L.; De Lira, C.; Andrade, M. Knee isokinetic muscle strength and balance ratio in female soccer players of different age groups: A cross-sectional study. Phys. Sportmed. 2020, 48, 105-109. [CrossRef] 
19. Armstrong, N.; Mcmanus, A.M. Physiology of elite young male athletes. In The Elite Young Athlete; Karger: Basel, Switzerland, 2011; Volume 56, pp. 1-22.

20. Malina, R.M. Maturity status and injury risk in youth soccer players. Clin. J. Sport Med. 2010, 20, 132. [CrossRef]

21. Renshaw, A.; Goodwin, P.C. Injury incidence in a Premier League youth soccer academy using the consensus statement: A prospective cohort study. BMJ Open Sport Exerc. Med. 2016, 2, e000132. [CrossRef]

22. Impellizzeri, F.M.; Bizzini, M.; Rampinini, E.; Cereda, F.; Maffiuletti, N.A. Reliability of isokinetic strength imbalance ratios measured using the Cybex NORM dynamometer. Clin. Physiol. Funct. Imaging 2008, 28, 113-119. [CrossRef]

23. Mota, S.; Brito, J.; Passos, E.; Marques, E.; Mota, J.; Seabra, A.; Rebelo, A. Variation of isokinetic strength and bone mineral density in youth portuguese soccer players with age. Open Sports Sci. J. 2010, 3, 49-51. [CrossRef]

24. Andrade, M.S.; Junqueira, M.S.; Andre Barbosa De Lira, C.; Vancini, R.L.; Seffrin, A.; Nikolaidis, P.T.; Rosemann, T.; Knechtle, B. Age-related differences in torque in angle-specific and peak torque hamstring to quadriceps ratios in female soccer players from 11 to 18 years old: A Cross-sectional study. Res. Sports Med. 2021, 29, 77-89. [CrossRef]

25. Philippaerts, R.M.; Vaeyens, R.; Janssens, M.; Van Renterghem, B.; Matthys, D.; Craen, R.; Bourgois, J.; Vrijens, J.; Beunen, G.; Malina, R.M. The relationship between peak height velocity and physical performance in youth soccer players. J. Sports Sci. 2006, 24, 221-230. [CrossRef]

26. Price, R.; Hawkins, R.; Hulse, M.; Hodson, A. The Football Association medical research programme: An audit of injuries in academy youth football. Br. J. Sports Med. 2004, 38, 466-471. [CrossRef]

27. McGill, S.M. Low Back Disorders. Evidence Based Prevention and Rehabilitation; Human Kinetics: Champaign, IL, USA, 2002.

28. Lehance, C.; Binet, J.; Bury, T.; Croisier, J.-L. Muscular strength, functional performances and injury risk in professional and junior elite soccer players. Scand. J. Med. Sci. Sports 2009, 19, 243-251. [CrossRef]

29. Orchard, J.W. Intrinsic and extrinsic risk factors for muscle strains in Australian football. Am. J. Sports Med. 2001, 29, 300-303. [CrossRef]

30. Maly, T.; Zahalka, F.; Mala, L. Unilateral and ipsilateral strength asymmetries in elite youth soccer players with respect to muscle group and limb dominance. Int. J. Morphol. 2016, 34, 1339-1344. [CrossRef]

31. Iga, J.; George, K.; Lees, A.; Reilly, T. Cross-sectional investigation of indices of isokinetic leg strength in youth soccer players and untrained individuals. Scand. J. Med. Sci. Sports 2009, 19, 714-719. [CrossRef] [PubMed]

32. Ribeiro-Alvares, J.B.; Dornelles, M.P.; Fritsch, C.G.; De Lima-E-Silva, F.X.; Medeiros, T.M.; Severo-Silveira, L.; Marques, V.B.; Baroni, B.M. Prevalence of hamstring strain injury risk factors in professional and under-20 male football (soccer) players. J. Sport Rehabil. 2020, 29, 339-345. [CrossRef] [PubMed]

33. Read, P.J.; Jimenez, P.; Oliver, J.L.; Lloyd, R.S. Injury prevention in male youth soccer: Current practices and perceptions of practitioners working at elite English academies. J. Sports Sci. 2018, 36, 1423-1431. [CrossRef] [PubMed] 